\title{
DECLÍNIO ORGANIZACIONAL E CONTEXTO EM ORGANIZAÇÃO RELIGIOSA: A IGREJA UNIVERSAL DO REINO DE DEUS
}

\section{RESUMO}

As organizações religiosas estão em bastante evidência, apresentam modelos de gestão variados e não têm garantia de sucesso. Algumas teorias de Administração são generalizáveis às igrejas, mas elas embutem também especificidades e enfrentam desafios (nis so nem se distinguem das empresas que visam ao lucro). Na Administração, a pesquisa sobre tais organizações é reduzida, e sua magnitude muito menor do que a que elas têm na vida de boa parcela da humanidade e da sociedade em geral. Por aí, este artigo contempla o declínio organizacional. Foca a Igreja Universal do Reino de Deus (IURD) no período entre 2000 e 2010, seu contexto e suas especificidades. Realizou-se um estudo de caso, com descrição e suporte bibliográfico. Os resultados sugerem, como motivos para a decaída da IURD a mudança do perfil de sua liderança, a concorrência acirrada de igrejas com características similares e mais novas (em especial, a Igreja Mundial do Poder de Deus), e o crescimento de fiéis evangélicos "genéricos" e das pessoas sem religião.

Palavras-chave: Declínio Organizacional. Igrejas. Igreja Universal do Reino de Deus. Liderança Carismática. Burocracia.

\section{ORGANIZATIONAL DECLINE AND CONTEXT IN RELIGIOUS ORGANIZATION: THE UNIVERS AL CHURCH OF THE KINGDOM OF GOD}

\begin{abstract}
Religious organizations are in evidence, management models varied and are no guarantee of success. Management theories are generalizable to churches, but they are also specifically specific and face challenges (in this they are not unlike profit-making companies). In the Administration, a research on such organizations is reduced, and its magnitude much smaller than is the life of good portion of humanity and of society in general. For that reason, this article contemplates the organizational decline. It focuses on the Universal Church of the Kingdom of God (IURD) in the period between 2000 and 2010, its context and its specificities. A case study was carried out, with bibliographic description and support. The results suggest, as from a decline in the leadership of the IURD, the concurrent competition of churches with similar and newer characteristics (especially a World Church of God's Power) and the growth of "generic" Evangelical believers, E of people without religion.
\end{abstract}

Keywords: Organizational Decline. Churches. Universal Church of the Kingdom of God. Charismatic Leadership. Bureaucracy. 


\section{DECLINIO ORGANIZACIONAL Y CONTEXTO EN ORGANIZACIÓN RELIGIOS A: LA IGLESIA}

\section{UNIVERSAL DEL REINO DE DIOS}

\section{RESUMEN}

Las organizaciones religiosas están en bastante evidencia, presentan modelos de gestión variados y no tienen garantía de éxito. Algunas teorías de Administración son generalizables a las iglesias, pero ellas embutidan también especificidades y enfrentan desafíos (en eso ni se distinguen de las empresas que apuntan al lucro). En la Administración, la investigación sobre tales organizaciones es reducida, y su magnitud mucho menor que la que tienen en la vid a de buena parte de la humanidad y de la sociedad en general. Por eso, este artículo contempla el declive organizacional. Foca la Iglesia Universal del Reino de Dios (IURD) en el período entre 2000 y 2010, su contexto y sus especificidades. Se realizó un estudio de caso, con descripción y soporte bibliográfico. Los resultados sugieren, como motivos para la decaída de la IURD el cambio del perfil de su liderazgo, la fuerte competencia de iglesias con características similares y más nuevas (en particular, la Iglesia Mundial del Poder de Dios), y el crecimiento de fieles evangélicos " genéricos "y de las personas sin religión.

Palabras clave: Declinación Organizacional. Iglesias. Iglesia Universal del Reino de Dios. Liderazgo Carismático. Burocracia.

Max Nunes Murtinho ${ }^{1}$ Fernando Marcos Bonnemasou Moreira de Castilho ${ }^{2}$ André Torres Urdan ${ }^{3}$

\footnotetext{
1 Doutorando do Programa de Pós-Graduação em Administração da Universidade Nove de Julho - PPGA/UNINOVE. Profess or da Universidade Federal de Mato Grosso - UFMT. Brasil. E-mail: maxmurtinho@ @hotmail.com

${ }^{2}$ Doutorando do Programa de Pós-Graduação em Administração da Universidade Nove de Julho - PPGA/UNINOVE. Professor da Universidade Federal de Mato Grosso - UFMT. Brasil. E-mail: fcastilhobr@gmail.com

${ }^{3}$ Doutor em Administração pela Faculdade de Economia, Administração e Contabilidade da Universidade de São Paulo - FEA/USP. Professor do Programa de Pós-Graduação em Administração da Universidade Nove de Julho PPGA/UNINOVE. Brasil. E-mail: andre.torres@uni9.pro.br
} 


\section{INTRODUÇÃO}

A pesquisa sobre declínio organizacional, a despeito de sua ascendência, perde em preferência para pesquisas sobre crescimento e sucesso organizacional (Serra, Ferreira \& Almeida, 2013). Tal tendência pode estar associada ao caráter negativo do tema (Serra, Pinto, Guerrazzi \& Ferreira, 2017), à dificuldade na obtenção de dados (Torres, Serra, Almeida \& Ferreira, 2013), à imprecisão do conceito (Bruton, Oviatt, \& White, 1994) ou ainda, à elevada quantidade de definições e mensurações para o conceito (Trahms, Ndofor \& Sirmon, 2013). Ademais, a investigação a respeito desse decaimento ainda é relativamente jovem, com muitas abordagens. A falta de integração e consistência nesse corpo teórico, apontada um par de décadas atrás (Sá, 1995), ainda não foi superada.

No artigo seminal sobre declínio organizacional, Whetten (1980), alertava os pesquisadores a dar maior atenção ao fenômeno do declínio. Desde então, a pesquisa vem se expandindo e seguindo diversas abordagens. Numa delas, o declínio é uma fase do ciclo de vida organizacional (Quinn \& Cameron, 1983). Outra contempla indicadores (Hambrick \& D’Aveni, 1988; Argenti 1976). Há aquela dedicada aos processos de turnaround, de superação da deterioração (Bibeault, 1982). A relação entre o declínio e o gestor de topo é bem pesquisada (Hambrick \& Schecter, 1983; Hall \& Mansfield, 1971; Hambrick \& Mason, 1984; Hofer, 1980). Alguns estudos recentes almejam uma abordagem mais integrada do fenômeno, como se dá com a caracterização do declínio, a inclusão de estratégias de turnaround e, as situações de desinvestimento (Serra $e t$ al. 2017).

Na administração, a pesquisa sobre igrejas é reduzida, e sua magnitude muito menor do que a que elas têm na vida de boa parcela da humanidade e da sociedade em geral. Por aí, este artigo contempla o declínio organizacional de igrejas. Entende-se relevante essa opção. Vale acrescentar a importância de pesquisas que se baseiam em fenômenos, a julgar pela baixa relação entre a produção acadêmica em administração com os dilemas do mundo real (Serra 2017). Além disso, são escassas as pesquisas que possuem organizações religiosas como objeto de investigação (Serafim, Martes \& Rodriguez, 2012).

Miram-se, de modo mais preciso, as igrejas Cristãs Neopentecostais. Muito do sucesso dessas organizações, expõem Pires e Jesus (2014), advém do foco nos anseios existencialistas da sociedade capitalista e pós-moderna. Suas estratégias possuem alto teor de pragmatismo e provocam bons resultados para os fiéis que, em sua maioria, possuem estilo de vida materialista e consumista. Tais características, segundo Carreiro (2007), aproximam as Neopentecostais das organizações que visam o lucro.
Toma-se neste artigo a Igreja Universal do Reino de Deus (IURD), instituição fundada no Brasil e que se espalhou pelo Mundo. Conforme o Censo brasileiro de 2010, a IURD é a maior denominação Neopentecostal do país. Sua teologia, não nega elementos básicos da fé Cristã, porém realça as curas física e espiritual e a Teologia da Prosperidade (Ferrari, 2007; Oro, 2011).

Diante disso, apresenta-se o seguinte questionamento: Porque a Igreja Universal do Reino de Deus apresentou declínio no período entre 2000 e 2010 após vertiginoso crescimento na década anterior? $\mathrm{O}$ objetivo do artigo, portanto, é investigar o contexto e as especificidades do declínio da Igreja Universal do Reino de Deus no período entre 2000 e 2010. No método, se empreende um estudo de caso, com descrição e apoio bibliográfico. Os dados sobre crescimento e declínio da IURD tiveram como fonte os censos demográficos do IBGE referentes ao período em análise.

Doravante, se sucedem seis seções, além desta Introdução. A segunda, revisa a literatura sobre o declínio organizacional. A terceira expõe o método e os procedimentos empíricos. A quarta descreve a IURD, seu início, o perfil de sua gestão, suas estratégias e seu declínio. A quinta discute possíveis motivos da queda da IURD. A sexta seção traz considerações finais, limitações e recomendações para novos estudos.

\section{REFERENCIAL TEÓRICO}

Embora 'declínio organizacional' exprima uma ideia simples, para esse conceito há variadas definições. Para Greenhalgh (1982), por exemplo, além da piora dos principais indicadores da empresa (tamanho físico, força de trabalho, participação de mercado, ativos, produção, etc.), o declínio se exprime pela menor capacidade de adaptação e/ou de domínio do âmbito de mercado em que a organização compete. Já Levy (1986) relaciona o declínio com essa maior dificuldade de adaptação. Koksal (2002) acrescenta o caráter temporal do declínio, como sintomas que emergem em algumas fases da trajetória organizacional. Quinn \& Cameron (1983) e Greiner (1972) veem o declínio como fase do ciclo de vida da empresa. Mas também é interpretado como um processo natural, após se atingir um pico (Mintzberg, 1984).

No processo de declínio, sintomas frequentes são os conflitos, a rigidez, a centralização e formalização excessiva, a diminuição do moral, da participação, do comprometimento e da influência da liderança, a perda da capacidade de inovação e do planejar o longo prazo (Whetten, 1987).

O declínio não pode ser considerado como o simples oposto ao sucesso organizacional (Serra et al., 
2017). É que o declínio, além de suas especificidades, vai além da redução da participação de mercado ou da competitividade, incluindo a estagnação, traço recorrente em empresas com mais passividade e rigidez (Whetten, 1980), que provoca imobilidade ambiental e ausência de inovação (Miller \& Friesen, 1984).

Tem-se como seminal a obra de Whetten (1980). Mas os estudos de Hambrick e D'Aveni (1988) e Bibeault (1982), foram as de maior impacto em um levantamento bibliométrico (Serra et al., 2017). Hambrick e D'Aveni (1988) investigaram os motivos determinantes do declínio da empresa. Bibeault (1982) focou o processo de turnaround, com as estratégias capazes de atenuar o declínio e até trazer de volta o crescimento e a evolução.

Sobre o fenômeno do declínio, há estudos sobre a influência do ambiente sobre o declínio (Starbuck, Greve \& Hedberg, 1978; Smart \& Vertinsky, 1977), a gestão de risco (Thompson, 1967), definição de tipologias de declínio (Zammuto \& Cameron, 1985) e a distinção entre declínio e estagnação (Bozeman \& Slusher, 1979). Alguns investigam os antecedentes do declínio (Altman \& Hotchkiss, 1983; Argenti, 1976), a influência estrutural no declínio (Pfeffer \& Salancick, 1978), uma influência mais robusta das ações gerenciais sobre os eventos ambientais em processos de turnaround (Hambrick \& Schecter, 1983; Hall \& Mansfield, 1971) e respostas em meio a situações de declínio (Hambrick \& Mason, 1984; Hofer, 1980).

Ao esforço de teorização acerca do declínio servem a Teoria da Dependência (Pfeffer \& Salancick, 1978), os efeitos da rigidez da ameaça no comportamento organizacional (Staw, Sandelands, \& Dutton, 1981), a Ecologia Organizacional (Hannan \& Freeman, 1984, 1989), a Teoria da Contingência (Thompson, 1967), Teoria Comportamental da Empresa (Cyert \& March, 1963), entre outras.

Ainda sobressaem múltiplas pesquisas que relacionam o declínio da organização com a gestão de topo (por exemplo Altman \& Hotchkiss, 1983; Gilson, 1989; Boeker, 1992; Cameron, Kim, \& Whetten, 1987; Hambrick \& D'Aveni, 1992; Moulton \& Thomas, 1993; Sutton \& Callahan, 1987). Incide um impacto significante da gestão em tal declínio. Um dos maiores desafios gerenciais é o reconhecimento dos problemas da organização (Whetten, 1980; Scott, 1976) e agir de forma eficaz diante do problema. O decisor, ao responder ao declínio, pode até piorar o estado desfavorável da organização (Hedberg, Nystrom e Starbuck, 1976). Quando isso ocorre, há uma tendência de dominação de forças políticas internas à organização em face do ambiente (Mintzberg, 1985; Hardy, 1989).

Entre 2003 e 2014, a literatura acadêmica versa mais estratégias e ações de turnaround, opções de desinvestimento e a caracterização do declínio (Serra et al. 2017). As maiores limitações dessa pesquisa recaem na dificuldade de acesso a dados empíricos (Torres et al. 2013; Serra et al. 2017), a imprecisão do conceito (Bruton, Oviatt, \& White, 1994), distância do lapso analisado, diversidade de medidas (Trahms et al., 2013), e imprecisão quanto ao período de real declínio (Barker \& Mone, 1994; Hambrick \& Schecter, 1983; Robbins \& Pearce, 1992).

No geral, a comunidade acadêmica segue bem distantes de um entendimento efetivo desse fenômeno do declínio. O fluxo de pesquisas está longe de uma maturidade e as diversas abordagens carecem de integração entre si e mesmo de consistência. Proliferam conceitos e interpretações. Além disso, o suporte empírico ainda é preliminar. Em especial, o declínio ocorre por diversos motivos, os quais dependem do tipo de organização e da linguagem adotada (Sá, 1995). Por tudo isso, se impõe elucidar plenamente porque organizações, mesmo tendo sido bem-sucedidas, entram em declínio (Serra, Ferreira \& Almeida, 2013). Tal é a questão orientadora do estudo empírico deste artigo, cujo método se encontra a seguir.

\section{MÉTODO}

Optou-se aqui por um estudo de caso, de caráter qualitativo, longitudinal, bibliográfico e descritivo. A pesquisa qualitativa, conforme Silva e Menezes (2001), considera haver uma relação dinâmica entre o mundo real e o sujeito, isto é, um vínculo indis sociável entre o mundo objetivo e a subjetividade do sujeito que não pode ser traduzida em números. Por sua vez, defendem Torres et al. (2013), a pesquisa em declínio organizacional é tendencialmente longitudinal, cobrindo a evolução da organização ao longo tempo de manifestação do declínio.

Em relação aos dados e informações, trata-se de dados secundários, recorrendo-se à fonte bibliográfica, já tornada pública em relação ao tema de estudo, desde publicações avulsas, boletins, jornais, revistas, livros, pesquisas, monografias, teses, material cartográfico, etc (Lakatos \& Marconi, 1991). É descritivo por se caracterizar população e/ou fenômeno e se, estabelecer relações entre variáveis e fatos (Martins, 2000).

A descrição da IURD incluirá fatores internos e externos. Os internos são o contexto interno, a estrutura, as características gerenciais e algumas estratégias da Igreja. Nos fatores externos, se prioriza a concorrência com outras igrejas similares.

A busca bibliográfica foi realizada no site de busca Google Acadêmico, (https://scholar.google.com.br) e pelas bases de dados Web of Science e Scopus, ambos acessados pelo Portal de Periódicos da Capes (http://www.periodicos.capes.gov.br/). Aproveitou-se bastante para a identificação dos principais artigos sobre declínio organizacional a bibliometria de Serra et al. (2017). Os dados a respeito do crescimento e declínio tanto da IURD quanto de seus principais concorrentes provieram dos censos demográficos 
realizado pelo Instituto Brasileiro de Geografia e Estatística (IBGE, 1991; 2000; 2010). O período de análise da IURD se estende entre anos 2000 e $2010 \mathrm{em}$ função de ser o período em que há um processo de declínio.

Dados censitários para Jacob, Hees, Waniez \& Brustlein (2003), têm as vantagens do caráter exaustivo, da grande cobertura geográfica e da elevada qualidade. Todavia, nesta pesquisa, nos censos consultados, a pergunta sobre religião ou culto existe apenas num questionário mais detalhado, que é aplicado uma amostra. O grande desafio na construção do artigo foi a escassez de dados quantitativos que caracterizassem o crescimento e o declínio da IURD. É evidente a qualidade dos dados de um censo populacional, ainda que, os dados sobre religião tenham um caráter amostral, mas praticamente nenhum outro dado secundário aborda números religiosos em tamanha amplitude. Dados de crescimento de templos ou faturamento das igrejas até poderiam servir de proxy, mas, ou são muito difíceis de conseguir ou não são confiáveis estatisticamente dificultante uma investigação com mais rigor científico. Daí resulta a escolha do número de fieis da IURD como informação vital para descrever seu crescimento e declínio. Reconhece-se certo nível de precariedade nos dados, não por sua confiabilidade estatística, mas por ser espaçados demais no tempo (10 anos). Ainda assim, uma cuidadosa triangulação de informações sobre o contexto e as especificidades da liderança da IURD, seus desafios como excesso de burocracia e maior concorrência possibilitam levantar algumas considerações.

A caracterização da IURD e de suas estratégias foram, em grande medida, calcados em artigos e livros de outras áreas e ciências, como a Sociologia da Religião, Teologia e Filosofia (Mariano, 2004; Neri, 2011; Rocha \& Zorzin, 2012; Campos, 2011; Freston, 1993; Carreiro, 2007), haja vista a escassez de trabalhos na Administração pertinentes a igrejas (Serafim, Martes \& Rodriguez, 2012).

\section{IGREJA UNIVERSAL DO REINO DE DEUS}

Esta seção, a respeito da IURD, compreende início e crescimento, o perfil de sua gestão, principais estratégias e seu declínio.

\section{Neopentecostalismo, Fundação e Expansão da IURD}

As igrejas Protestantes não constituem massa homogênea e, então, a análise delas requer classificálas em suas características fundamentais. Contam, entre outros critérios, o período de surgimento, a teologia e o comportamento (Mariano, 2004). A Reforma Protestante surgiu no Século XVI, como um movimento interno da Igreja Católica movido por católicos que desejavam inicialmente reformá-la, sem, necessariamente, romper. Seus maiores representantes, são Martinho Lutero e João Calvino. Defendem essencialmente a não intervenção de mediadores humanos entre Deus e o crente, questionam a autoridade do Papa como líder maior do Cristianismo e defendem que a salvação é unicamente pela graça concedida pela fé em Jesus Cristo, e não por obras humanas, conforme defendida pela teologia Católica (Tillich, 2000).

Num nível mais micro, os Protestantes são divididos nos grupos de igrejas Tradicionais, Pentecostais e Neopentecostais (Freston, 1993; Mariano, 1996).

As igrejas Tradicionais nasceram na Europa com o Movimento da Reforma do Século XVI. As Pentecostais se originam do início do Século XX nos Estados Unidos. Já as Neopentecostais, despontaram no Brasil, a partir da década de 1970, se distinguindo bem dos outros dois. Os Tradicionais e Pentecostais, apesar de suas diferenças, fundamentam sua teologia em três pilares do Cristianismo: divindade de Jesus Cristo, arrependimento e salvação. Os Neopentecostais, por seu lado, não negam esse tripé evangélico, todavia, focam a teologia em exorcismo, prosperidade e cura (Dias, 2011). A ênfase nas curas milagrosas se vincula ao combate aos demônios (Mariano, 2004; Oro, 2011). Seus cultos utilizam em grande medida testemunhos de curas e, sempre que possível, utilizam a comunicação de massa, combinando marketing e até política (Oro, 2011).

Muito do sucesso das igrejas Neopentecostais resulta do foco nos anseios existenciais da sociedade capitalista e pós-moderna (Campos, 2006; Pires \& Jesus, 2014; Ferrari, 2007). Suas estratégias possuem alto teor de pragmatismo, provocando bons resultados em fiéis que, em sua maioria, possuem estilo de vida materialista e consumista. Campos (1999, p. 356), afirma que "frequentemente, essa rápida expansão procura-se legitimar pela lógica capitalista de que os resultados obtidos justificam os meios empregados". Atualmente, a maior das igrejas Neopentecostais em número de fiéis é a Igreja Universal do Reino de Deus (IURD). Ela teve elevado crescimento em poucas décadas de existência (Campos, 1999; Carreiro, 2007).

A IURD foi constituída no Rio de Janeiro, RJ, em 1977 por três pessoas: Edir Macedo de Bezerra; seu cunhado, Romildo Ribeiro Soares (hoje conhecido publicamente como R. R. Soares) e Roberto Augusto Lopes. Todos vinham da Igreja Pentecostal Nova Vida (Campos, 1999; Carreiro, 2007). Três anos depois, Macedo se desentende com o cunhado, R. R. Soares. Em 1986, Roberto Augusto Lopes segue para a política. Edir Macedo, então, se torna o único líder eclesiástico da IURD (Carreiro, 2007).

Em 1986, Renato Suhett (um ex-bispo da IURD) assume a responsabilidade pela igreja no Brasil. Edir Macedo abre um templo em Nova York, Estados Unidos. A igreja crescia e mais e mais bispos iam 
sendo consagrados. Um colégio de bispos foi formado e Edir Macedo the passa parte de seu poder. Um corpo de gestão foi escolhido com muito cuidado, haja vista as dimensões gigantescas que a IURD atingia (Carreiro, 2007).

A distribuição da proporção de fiéis da IURD no Brasil no ano de 1991 (Figura 1) mostra uma distribuição bem irregular pelo território. Sua presença era forte na cidade do Rio de Janeiro, sobretudo nos municípios de sua região metropolitana, além de Cabo Frio, Macaé e Campos. Também se destacava em Salvador e outras cidades do Nordeste (Jacob, Hees \& Waniez, 2013).

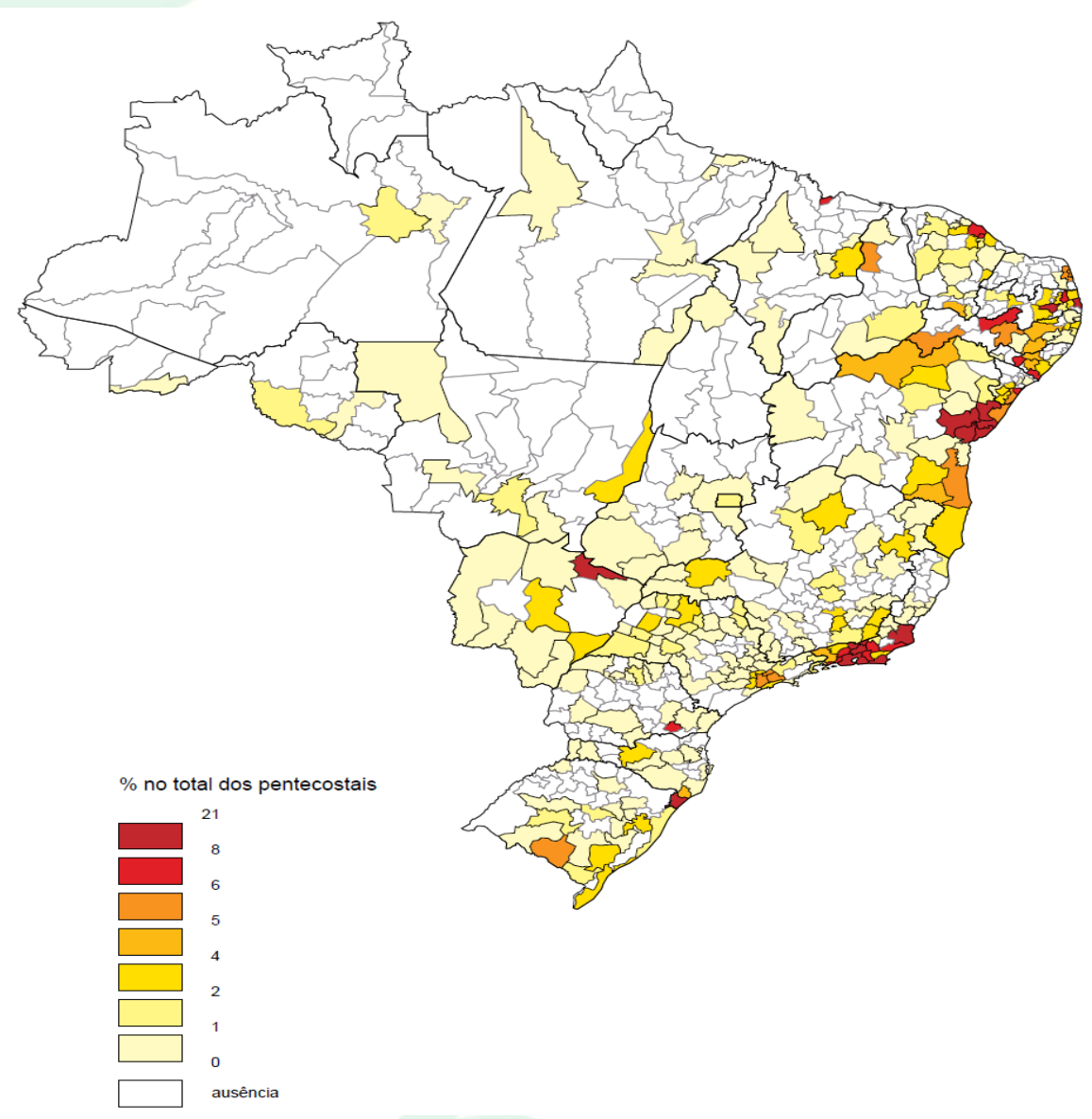

Figura 1 - Distribuição da proporção de fiéis da IURD no total de cidadãos Pentecostais no território do Brasil em 1991 Fonte: Jacob, Hees \& Waniez (2013), com dados do IBGE (1991).

Até 1995, segundo Campos (1999) se estima que a IURD abriu 2014 templos no Brasil e 236 em outros 65 países, abrindo espaço para a frequência de aproximadamente quatro milhões de fiéis. A média mensal de templos inaugurados nesse período foi de 9,3 por mês no Brasil e 1,9 no exterior.

Já o mapa da IURD no Brasil - equivalente ao da Figura 1 - baseado no Censo de 2010 está na Figura 2. Ali, se reduzira o contingente de fiéis, mas se passou a ter a dispersão deles por todo o território nacional. Esse padrão de dispersão talvez se explique pela disseminação de filiais da Rede Record de televisão (Jacob, et al., 2013), que se tornou o principal meio de comunicação de massa da IURD. A dispersão de templos e a disseminação na comunicação, no entanto, não foi capaz de evitar a queda de fieis no final da década de 2000. 


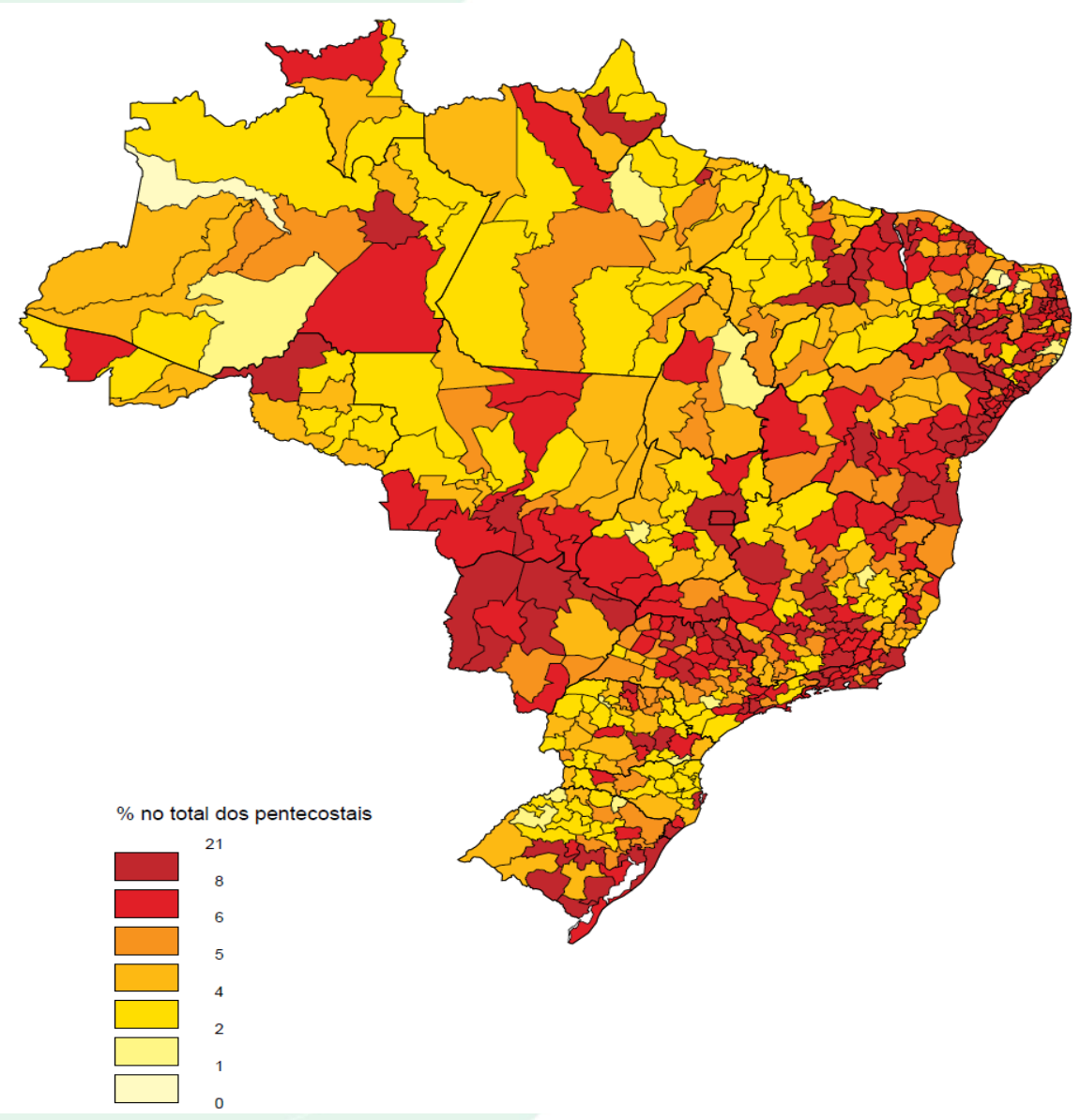

Figura 2 - Distribuição da proporção de fiéis da IURD no total de cidadão Pentecostais no território do Brasil em 2010 Fonte: Jacob, Hees \& Waniez (2013), com dados do IBGE (2010).

A IURD se transformou em uma espécie de teocracia, subordinada a um homem ou a um pequeno grupo, que monopoliza autoritariamente o poder de gestão. Nesse modelo, a obediência, obtida por persuasão ou mesmo coerção, é o alicerce da IURD como instituição (Campos, 2006).

A maioria dos pastores da IURD não possui formação teológica. Além disso, segundo Rogério Rodrigo Silva (apud Campos, 2006), apenas 5\% deles possuem mestrado ou doutorado, percentual que sobe para 17\% nas igrejas Protestantes Tradicionais. Um dos pastores da IURD, José Cabral, ao replicar palavras de Edir Macedo, questionou: "é na companhia de outros pastores mais experimentados que um pastor neófito (pastor auxiliar) tem todos os elementos para aprender a tirar uma boa coleta, pedir a Deus por um milagre e realizar um exorcismo". Ele, por isso, questiona: "para que então uma formação teológica com aulas de hebraico, grego, exegese e hermenêutica se algumas aulas de práticas de oratória, etiqueta e gerência financeira de um templo bastam?" (Campos, 2006, p. 134).

A IURD, conforme Carreiro (2007), orienta-se por uma ideologia derivada do laissez-faire. Ideologia em que o objetivo único da empresa é o lucro máximo, sendo ele, na religião, o crescimento de fiéis. De fato, uma das principais características das igrejas Neopentecostais é o crescimento acelerado.

No Grande Rio de Janeiro, entre os fiéis da IURD sobressaem a baixa renda, a pouca escolaridade e cor de pele mais escura. Os fiéis que ganham até dois salários mínimos são $63 \%$ do todo, ante $58 \%$ entre os evangélicos e $45 \%$ na população do Brasil. Apenas $21 \%$ da população brasileira têm quatro anos ou menos de escolaridade, taxa que entre evangélicos sobe para $39 \%$ e, na IURD, bate em $50 \%$. No que tange à cor de pele, os brancos são $60 \%$ da população, $49 \%$ dos evangélicos e $40 \%$ na IURD. Esta base popular da IURD é conjugada com um poderio organizacional decorrente da estrutura hierárquica rígida, do cacife político, da arrecadação financeira (equivalente ao da $34^{\mathrm{a}}$ maior empresa privada do país) e a ampla e articulada rede de mídia (ISER, 1996 apud, Freston, 1999).

\section{Estratégias da IURD}

Uma das estratégias da IURD, desde a fundação, é evitar que suas igrejas implantadas no exterior sejam conduzidas por pastores nativos. Nessas 
posições, portanto, a maioria dos pastores é brasileira e expatriada por ordem direta de Edir Macedo. O objetivo é evitar o risco de desagregação resultante de influência de líderes estrangeiros locais. Muitos desses pastores da IURD no exterior dominam apenas o português, parte deles também o espanhol. Por isso, a maioria dos fiéis - nos templos da IURD no exterior são imigrantes latinos (Campos, 2006).

Outra estratégia - de similar natureza aplicada pela IURD tanto no Brasil quanto no exterior - é a desterritorialização dos líderes. Envolve um rodízio permanente dos pastores, com vistas a aumentar a dependência deles em relação à Igreja, limitando a construção mais independente de suas carreiras. Estratégia que ajuda ainda a evitar que fiéis locais se identifiquem excessivamente com um determinado pastor, com que convivem diretamente, ocorrência essa que incidem em grande parte das desagregações religiosas (Campos, 2006).

Outra estratégia da IURD, conforme Campos (1999), é uma espécie de marketing transcendental, em que, atribui o crescimento da Igreja ao poder do Espírito Santo. Isso é perceptível em frases de Edir Macedo: "o documentário foi preparado sob a responsabilidade do Espirito Santo"; "enquanto este documentário estava sendo preparado a IURD não parou de crescer em todo o mundo"; "Atribuo à ação do Espírito Santo o crescimento da Igreja. Não se trata de marketing bem feito, boa administração, nem qualquer razão humana. É ação do Espírito Santo mesmo".

Além disso, a IURD sustenta seus cultos no tripé: teatro, templo e mercado. Antes busca a compreensão das características sociais dos fiéis e potenciais fiéis, numa prática similar ao diagnóstico, via pesquisa de mercado, realizado pelas organizações que visam ao lucro (Campos, 1997). A IURD, sob outro ângulo, se pauta pela tradição religiosa brasileira. No dizer de um intelectual seu "não nos orientamos por uma tradição evangélica europeia ou americana. Partimos da prática religiosa do povo" (Freston, 1999, p. 385).

Aí, se recorre a um marketing com bens de valor simbólico (Pereti, Coppeli \& Ferreira, 2011). Todavia, é crucial na gestão da IURD - como se dá com a estratégia de marketing de qualquer organização - que seu público-alvo seja solo fértil para sua atuação, suas práticas e suas relações de troca (Freston, 1999).

Todavia, a alta proporção de pobres (fruto da concentração de renda) no Brasil suporta o crescimento da IURD. A mensagem para esse estrato é que a miséria precisa estar lado a lado com a riqueza, de maneira que essa última seja tida como modelo de vida pelos menos favorecidos. Sendo is so mesmo verdade, o Brasil seria dos países mais acessíveis à pregação Neopentecostal, dada a acentuada concentração de renda (Ribeiro, 2005; Morais, Figueiredo \& Zanotta, 2004) e a enorme população.
A compreensão de Edir Macedo sobre a natureza da religiosidade brasileira, explica Refkalefsky (2006), é um fator importante para seu sucesso organizacional. Com isso, a IURD move-se a partir de e alinhada com as características da sociedade brasileira que the interessa. Nessa esfera, a abordagem do Neopentecostalismo no Brasil é esclarecida por Morais, Figueiredo e Zanotta (2004, p. 55):

o pentecostalismo, particularmente em sua versão neopentecostalista, participa desse processo de reencantamento do mundo e do novo modo de apresentação da religião em nossa sociedade, isto é, um modo marcadamente centrado nos problemas dos adeptos, sejam estes de ordem espiritual, afetiva ou financeira.

Ou seja, as igrejas Tradicionais e Pentecostais lutam para convencer a sociedade a abrir mão de um estilo de vida materialista. Promovem o autocontrole do corpo e do espírito, a rejeição do mundo como forma de aproximar-se de Deus. Diversamente, as igrejas Neopentecostais tomam as características da população como um dado e daí, delineiam ações para alcançar seus objetivos organizacionais, de modo similar ao da empresa que visa ao lucro.

A adequação da IURD às características da sociedade contemporânea, porém, não é absoluta. A IURD, de modo proativo, constrói uma realidade própria para seus fiéis, formando neles uma mentalidade que se coadune com sua doutrina e seus interesses (Resende, 2006). Na implantação dessa estratégia, o mais importante instrumento para persuadir e formar opinião são os bispos, pastores e líderes. Um exemplo desse convencimento é o mecanismo de transferência, pelo qual a IURD "molda" o julgamento do fiel, o transferindo para sua própria consciência, a fim de que ele se sinta um auto doutrinador (Resende, 2006).

No exterior, ao contrário de outras expressões do protestantismo Latino-Americano e africano, a IURD possui um poder político e uma força econômica capaz de lhe assegurar visibilidade, mesmo na Europa e nos Estados Unidos (Freston, 1999). No Cristianismo, o centro religioso também centraliza o poder econômico. Dessa forma, avulta o potencial da IURD para ultrapassar fronteiras, não só nacionais, mas ainda sociais, culturais e políticas.

Outra estratégia da IURD é a intensa utilização - para evangelizar - dos meios de comunicação de massa. A capacidade da IURD de se espraiar pelo Brasil se atrela à poderosa mídia que ela soube manobrar, principalmente com a televisão e o rádio. A Rede Record pertence à IURD e a localização de suas afiliadas acompanha suas prioridades de mercado no Brasil (Neri, 2011; Ribeiro \& Pinto, 2009).

Por fim, há a liderança carismática de Edir Macedo. O líder carismático distingue-se pela atração pessoal que é capaz de exercer sobre os liderados 
(Shamir, House \& Arthur, 1993), algo marcante no perfil de Edir Macedo (Nunes, 2007). Esse estilo de liderança é capaz de transmitir e compartilhar o carisma entre pequenos líderes e demais seguidores (Campos, 2011; Campos \& Junior, 2013). O líder carismático assume o papel de empreendedor carismático, protagonizando eventos como cruzadas evangelísticas ou programas cotidianamente veiculados na mídia (Oro, 2009). O conjunto sintético das estratégias da IURD, acima apontadas, se encontra na tabela 1 .

Tabela 1 - Lista de Estratégias Utilizadas pela IURD

\begin{tabular}{|l|}
\hline \multicolumn{1}{|c|}{ Estratégias } \\
\hline 1. Pastores brasileiros em igrejas fora do Brasil \\
\hline 2. Rodízio de pastores \\
\hline 3. Marketing com valor transcendental \\
\hline 4. Elevado teor de teatralidade nos cultos \\
\hline 5. Marketing de bens com valor simbólico \\
\hline 6. Adequação à tradição religiosa brasileira \\
\hline 7. Densa participação política \\
\hline 8. Uso dos meios de comunicação em massa \\
\hline 9. Liderança carismática de Edir Macedo \\
\hline
\end{tabular}

Fonte: elaboração dos autores.

\section{Declínio da Igreja Universal}

Após rápido crescimento na década de 1990, o total de fiéis da IURD caiu na década seguinte. O seu contingente de crentes, que era de 269 mil em 1990, passara para 2,1 milhões em 2000, porém recuou para 1,87 milhões em 2010 (aproximadamente 10\% de queda) (IBGE, 2010).

Ainda que a IURD, argumentam Jacob et al. (2013), tenha se tornado um símbolo das transformações religiosas do Brasil, com sua expansão rápida, a queda de sua participação de $12 \%$ (em 2000) para 7\% (no ano de 2010) do total de fiéis Pentecostais e Neopentecostais, representa uma redução expressiva de sua importância e atratividade religiosa.

A tabela 2 traz a ordem decrescente das principais igrejas Protestantes em função da variação da quantidade de fiéis no Brasil, no período de 2003 a 2009. Vê-se ali que as maiores igrejas Protestantes cresceram no interregno. Por sua vez, a IURD não só diminuiu, como enfrentou a segunda maior queda dentre todas as igrejas protestantes no Brasil (perdendo apenas, no indicador, para a Igreja Luterana). 
Tabela 2 - Ranking de Variação das Principais Igrejas Protestantes (2003 - 2009)

\begin{tabular}{|c|l|c|}
\hline Ordem & \multicolumn{1}{|c|}{ Igreja } & Variação \\
\hline 1 & Assembleia de Deus & $0,87 \%$ \\
2 & Batista & $0,21 \%$ \\
4 & Adventista do Sétimo Dia & $0,10 \%$ \\
5 & Metodista & $0,09 \%$ \\
6 & Mórmons & $0,08 \%$ \\
7 & Testemunhas de Jeová & $0,07 \%$ \\
8 & Quadrangular & $0,03 \%$ \\
9 & Legião da Boa Vontade & $-0,01 \%$ \\
10 & Menonita & $-0,01 \%$ \\
11 & Congregacional & $-0,03 \%$ \\
12 & O Brasil para Cristo & $-0,04 \%$ \\
13 & Deus é Amor & $-0,05 \%$ \\
14 & Casa da Benção & $-0,07 \%$ \\
15 & Presbiteriana & $-0,14 \%$ \\
16 & Congregação Cristã no Brasil & $-0,31 \%$ \\
17 & Universal do Reino de Deus & $-0,47 \%$ \\
& Luterana & $-0,92 \%$ \\
\hline
\end{tabular}

Fonte: Neri (2011)

\section{DISCUSSÃO}

Algumas reflexões se viabilizam com o mapeamento acima, de base bibliográfica, das estratégias e dos resultados da IURD. Das nove estratégias da IURD (tabela 1), apenas uma delas sofreu uma alteração notável no período subsequente ao de crescimento da Igreja: a liderança carismática. Todavia, à medida que a igreja aumentava seu porte, o estilo de liderança, a despeito dos esforços desse fundador, foi se tornando mais e mais burocrático (Nunes, 2007). A gestão de uma vasta e complexa organização, espalhada pelo Mundo, demandava esse outro estilo de liderança. A burocracia se caracteriza por ter objetivos fortemente vinculados a regras, normas e padrões de funcionamento (Merton, 1959), tender a oligarquizar o poder intraburocrático (Michels, 1949), possuir perfil antiinovador e reforçador do status quo, da estrutura burocrática (Mises, 1944), se acomodar com padrões mínimos (Gouldner, 1954) e apresentar baixa capacidade de autocorreção sistêmica, ancorando-se em estratégias conservadoras e formalistas de autoproteção (Crozier, 1979).

Tal transição não ocorre sem uma inicial resistência de Edir Macedo. Ele temia que a burocracia fizesse a IURD perder sua diferenciação, que tanto atraia seu público-alvo (Campos, 2006). A obediência ao líder carismático se estabelece não pela sua posição hierárquica ou por sua dignidade, mas por qualidades excepcionais percebidas pelos liderados; a influência líder-liderado, então, subsiste enquanto esse perfil permanece (Nunes, 2007). Parece, por exemplo, que Macedo enxerga o mundo como "um campo de batalha" (Campos, 2006), em que ele lidera o enfrentamento dos cristãos. Todavia, a passagem de uma liderança carismática para uma organização burocrática é uma enorme mudança e assim se deu na IURD, por is so gerando conflitos.

Recorre-se à literatura sobre a alteração do estilo da liderança em organizações religiosas. Igrejas que crescem sob a influência de um líder carismático tendem, segundo Bourdieu (2007), a se tornar ortodoxas, identificando-se com hierarquias e dogmas e, dessa forma, fadada a suscitar uma nova reforma.

Mas o carisma do líder também pode ser um elemento de desagregação na igreja. É que o poder carismático se estende também aos líderes menores, que podem ser tentados a exercer sua missão por meio da função de uma igreja própria ou a transferência para outra organização religiosa. Um notável exemplo dessa ocorrência é a Igreja Mundial do Poder de Deus (IMPD), também Neopentecostal. Seu líder, 
Waldemiro Santiago provém da IURD e também se notabiliza pelo carisma (Nunes, 2007).

Indo além, a IMPD, fundada em 1998, guarda diversas similaridades com a IURD. Ela enfatiza a prática de "curas milagrosas" em seus cultos e adota uma perspectiva altamente existencialista (atenção à mundanidade da realidade concreta do indivíduo). Há semelhança na programação semanal, no estilo inflamado e persuasivo dos pregadores e nas grandes demonstrações de curas ocorridas nos cultos (Pereira \& John, 2015). A IURD, então, passa a ter uma concorrência que reproduz as suas práticas. As "tardes da vitória e libertação", a utilização de sal grosso e as sessões de descarrego, são alguns exemplos (Rocha, 2011). Tem-se uma competição entre organizações isomórficas, porém em fases diferentes do ciclo de vida.

Não que Edir Macedo tenha deixado de estar à frente da IURD; ele segue sendo seu líder máximo. Mas muito da pregação da igreja emana de incontáveis outros bispos e milhares de pastores. Isso atenuou provavelmente o reconhecimento e a influência do estilo carismático e, por consequência, uma parcela de fiéis mais propensos a esse estilo se sentiu menos ligada ou se desligou da igreja (Resende, 2006). O Censo Demográfico de 2010 trouxe a primeira contagem de adeptos da IMPD: cerca de 315 mil pessoas. Estima-se que $30 \%$ dos fiéis e dos pastores da IMPD tenham vindo da IURD (Kachani, 2012).

Olhando para a frente, à medida que a IMPD cresça, um processo de burocratização também pode atingi-la. E quem sabe o declínio experimentado pela IURD sobre a IMPD também se abata (Nunes, 2007; Resende, 2006).

Despontam, pelo exposto, duas possíveis variáveis explicativas do declínio da IURD: a mudança de seu estilo de liderança e a desvantagem por concorrer, com uma liderança mais burocrática, com outra igreja similar, mas ainda fortemente carismática.

O declínio da IURD se caracteriza como um legítimo exemplo de declínio organizacional, pois apresentam sintomas consolidados na literatura do declínio. Por exemplo, a) a redução na participação do "mercado" (Greenhalgh, 1982), entende-se mercado como o número de fieis; e, b) dificuldades para manter o domínio (Levy, 1986) seja por motivos externos como a concorrência de outras denominações neopentecostais, ou por motivos internos, como as consequências do uso crescente da burocracia.

Os aspectos negativos, consequências do uso excessivo de burocracia, se correlacionam com alguns sintomas de declínio apresentado no trabalho seminal de Whetten (1987), por exemplo: a) formalização excessiva; b) perda de capacidade de inovação; c) rigidez; d) aumento de conflitos etc. É perceptível o quanto estes itens compõem vários dilemas da liderança da IURD. A preocupação de Edir Macedo com a formalização institucional e perda da característica carismática, a dificuldade adotar métodos inovadores nos cultos e evangelização sem que a mesma esteja sendo exaustivamente plagiada por denominações concorrentes, e, até mesmo a ocorrência de rupturas promovidas por desavenças são alguns exemplos.

Outro motivo para a queda da IURD pode ser o aumento, no Brasil, de evangélicos genéricos (sem vínculo com uma igreja específica) ou de pessoas sem religião. De acordo com a POF (Pesquisa de Orçamento Familiar), do IBGE, entre 2003 e 2009, o número de evangélicos genéricos aumentou de $4 \%$ para $14 \%$. Além disso, aproximadamente $50 \%$ da população brasileira frequenta cultos religiosos de mais de um credo (Neri, 2011). Essa dinâmica impacta diversas igrejas e denominações. Uma delas, a vertente Carismática da Igreja Católica, que possui algumas das características das igrejas Neopentecostais (Neri, 2011).

Por fim, é deduzível que um problema que as igrejas Neopentecostais faceiam é a dificuldade em manter, no longo prazo, um modelo de evangelização coerente entre as promessas e os resultados reais. As exageradas promessas materialistas e imediatistas acabam não se sustentando por muito tempo. Fiéis que não conseguemas conquistas enfaticamente prometidas tendem à frustração e ao desânimo, propulsores do abandono da igreja. Os fiéis podem até se sentir enganados pela igreja e com ela revoltados. Não são poucos os casos de processos judiciais contra a IURD movidos por ex-fiéis que se sentiramlesados.

A pesquisa sobre declínio é dificultada pela natureza intricada do fenômeno e da amplitude dos construtos que nele interferem (Serra et al., 2017). Em face de tantas variáveis, contextos, tipos de organização e, medidas em jogo, é desafiador integrar esse emaranhado a ponto de compor uma teoria do declínio sólida e consolidada (Starbuck et al., 1978; Trahms et al., 2013; Argenti, 1976; Serra et al., 2017). Nesse rumo, espera-se que este artigo seja uma contribuição incremental, a lançar algumas luzes para o desenvolvimento teórico do declínio no específico contexto das organizações religiosas. Mas o tema, claro, tem a mesma alta importância para as organizações empresariais, âmbito em que a pesquisa não é menos insuficiente (Serafim, Martes \& Rodriguez, 2012).

\section{CONSIDERAÇÕES FINAIS}

O artigo ajudou à compreensão do declínio organizacional investigando o contexto e as especificidades do caso da Igreja Universal do Reino de Deus (IURD). Organização que após vertiginoso aumento da base de fiéis na década de 1990, conheceu pronunciada queda, nesse indicador, entre os anos 2000 e 2010.

$\mathrm{O}$ crescimento da IURD parece relacionado às suas estratégias: pastores brasileiros em templos no 
exterior; rodízio de pastores; marketing com valor divino; elevado teor de teatralidade nos cultos; marketing de bens com valor simbólico; adequação à tradição religiosa brasileira; densa participação política, uso dos meios de comunicação de massa; e liderança carismática do fundador Edir Macedo.

Entretanto, conforme a IURD crescia, aumentava-se a burocratização, afastando parcela dos fiéis especialmente sensíveis ao carisma. Soma-se a is so a ascensão de outra igreja Neopentecostal, a Igreja Mundial do Poder de Deus, sua principal concorrente, que tomou fiéis da IURD, principalmente os mais atraídos pela liderança carismática, saliente na IMPD. É preciso salientar também que, a disseminação dos meios de comunicação realizado pela IURD no período em análise, bem como a sua dispersão em número de templos no território nacional, não foram suficientes para impedir a queda do número de fieis.

Há ainda um crescimento de fiéis no Brasil dissociados de uma denominação específica, evangélicos genéricos, e também das pessoas sem religião. Pesam ainda as restrições de longo prazo da proposta evangelística da IURD, pois promessas de retorno garantido que não se confirmam levam à decepção e, no extremo, o abandono da igreja; eis a manifestação unitária do declínio organizacional.

A queda de fieis da IURD, unido ao contexto e especificidades descritas se caracteriza como um legítimo caso de declínio conforme aponta a literatura do tema. Apresentou indicadores de queda (Greenhalgh, 1982), dificuldade para manter o domínio (Levy, 1986), e evidenciando tendências similares a uma fase de queda de um Ciclo de Vida Organizacional (Quinn \& Cameron, 1983; Greiner, 1972).

A literatura sobre declínio, além de esparsa, analisa essencialmente organizações que visam ao lucro. Urge dispor de iniciativas de pesquisa que contemplem outras organizações como as religiosas e as sociais.

\section{Limitações Incidentes}

Várias são as limitações deste artigo. Não se almejou exaurir a identificação das variáveis influentes no declínio da IURD. Não há dados sobre religiões no nível nacional fora dos censos. Ainda que haja dados abrangentes e confiáveis, informações censitárias, referentes a grandes intervalos de tempo, reduzem as possibilidades analíticas. Uma série temporal anual, por exemplo, possibilitaria inferências mais sofisticadas em torno do objeto estudado. Também limitante foi a fonte bibliográfica sem a complementação de dados primários. Entrevistas com fiéis e pastores melhorariam a descrição das igrejas. Isso exigiria engenhosidade para contornar a indisposição e até pudor de religiosos em expor dados sobre sua organização. A própria literatura do declínio reconhece a dificuldade de acesso a dados empíricos (Torres et al., 2013; Serra et al., 2017); a imprecisão do conceito de declínio (Bruton, Oviatt \& White, 1994), e imprecisão ao período em que ocorre o declínio (Barker \& Mone, 1994). Para aprimorar o exame empírico dos determinantes do declínio organizacional com vistas à solidificação teórica seria recomendável um estudo de casos múltiplos. Por fim, após a divulgação dos resultados do próximo censo populacional brasileiro ter-se-á uma rica fonte para abordar a evolução da IURD e de outras organizações religiosas (em particular, a IMPD) em termos de declínio. Quanto mais se explicar o declínio, mais condições de ação gerencial deve haver para evitá-lo e superá-lo.

\section{REFERÊNCIAS}

Altman, E. I. \& Hotchkiss, E. (1983). Corporate financial distress and bankruptcy. Chichester: John Wiley \& Sons Inc.

Argenti, J. (1976). Corporate collapse: the causes and symptons. New York: John Wiley \& Sons Inc.

Barker, V. L. \& Mone, M. A. (1994). Retrenchment: cause of turnaround or consequence of decline? Strategic Management Journal, 15(5): 395-405.

Bibeault, D. B. (1982). Corporate turnaround: how managers turn losers into winners (Vol. 15). Maidenhead: McGraw-Hill.

Boeker, W. (1992). Power and managerial dis missal: scapegoating at the top. Administrative Science Quarterly, 37(3): 400-421.

Bozeman, B. \& Slusher, E. A. (1979). Scarcity and environmental stress in public organizations: a conjectural essay. Administration \& Society, 11(2): 335-355.

Bourdieu, P. (2007). A economia das trocas simbólicas. São Paulo: Perspectiva.

Bruton, G. D., Oviatt, B. M., \& White, M. A. (1994). Performance of acquisitions of distressed firms. Academy of Management Journal, 37(4): 972-989.

Cameron, K. S., Kim, M. U. \& Whetten, D. A. (1987). Organizational Effects of Decline and Turbulence. Administrative Science Quarterly, 32: 222-240.

Campos, L. S. (1997). Teatro, Templo e Mercado. Petrópolis: Vozes.

Campos, L. S. (1999). A Igreja Universal do Reino de Deus, um empreendimento religioso atual e seus modos de expansão (Brasil, África e Europa). Lusotopie, 355-367. 
Campos, L. S. (2006). Cultura, liderança e recrutamento em organizações religiosas - o caso da Igreja Universal do Reino de Deus. Organização em Contexto, 2(3):102-138.

Campos, R. B. C. (2011). O profeta, a palavra e a circulação do caris ma pentecostal. Revista de Antropologia,54(2): 1013-1049.

Campos, R. B. C. \& Junior, C. M. (2013) As formas elementares da liderança carismática: o verbo e a imagética na circulação do caris ma pentecostal. Mana 19(2): 249-276.

Carreiro, G. da S. (2007). Análise Sóciodesenvolvimental do crescimento Evangélico no Brasil. Tese de doutorado, Instituto de Ciências Sociais da Universidade de Brasília, Brasília, DF.

Cyert, R. \& March, J. G. (1963). A behavioral theory of the firm. Englewood Cliffs: Prentice-Hall.

Ferrari, O. A. (2007). Bispo S/A - A Igreja Universal do Reino de Deus e o exercício do poder. Ed: Avemaria.

Crozier, M. (1979). O fenômeno burocrático. Universidade de Brasília, Brasília, DF.

Dias, Z. M. (2011). Um século de religiosidade Pentecostal: algumas notas sobre a irrupção, problemas e desafios do fenômeno pentecostal. Horizonte, 22(9): 377-382.

Freston, P. C. (1993). Evangélicos e Política no Brasil: da constituinte ao impeachment. Tese de doutorado. Universidade Estadual de Campinas, Campinas, SP.

Freston, P. C. (1999). A Igreja Universal do Reino de Deus na Europa. Lusotopie, 383-403.

Gouldner, A. (1954) Patterns of industrial bureaucracy. London: Routledge \& Kegan Paul.

Greenhalgh, L. (1982). Maintaining organizational effectiveness during organizational retrenchment. Journal of Applied Behavioral Science, 18:155-170.

Greiner, L. (1972). Evolution and revolution as organizations grow. Harvard Business Review, 50(4): $37-46$.

Hall, D. T. \& Mansfield, R. (1971). Organizational and individual response to external stress. Administrative Science Quarterly, 16(4): 533-547.

Hambrick, D. C. \& Schecter, S. M. (1983). Turnaround strategies for mature industrial-product business units. Academy of Management Journal, 26(2): 231-248.
Hambrick, D. C. \& Mason,P. A. (1984). Upper echelons: the organization as a reflection of its top managers. The Academy of Management Review, 9(2): 193-206.

Hambrick, D. C. \& D’Aveni, R. A. (1988). Large corporate failures as downward spirals. Administrative Science Quarterly, 33(1): 1-23.

Hambrick, D. C. \& D’Aveni, R. A. (1992). Top team deterioration as part of the downward spiral of large corporate bankruptcies. Management Science, 38(10): 1445-1466.

Hannan, M. T. \& Freeman, J. (1984). Structural inertia and organizational change. American Sociological Review, 49(2): 149-164.

Hannan, M. T., \& Freeman, J. (1989). Organizational ecology. Zhurnal eksperimental'noi i teoreticheskoi fiziki. Cambridge: Harvard University Press.

Hardy, C. (1989). Strategies for Retrenchment and Turnaround: The Politics of Survival. New York : deGruyter.

Hedberg, B. L. T., Nystrom, P. C. \& Starbuck, W. H. (1976). Camping on seesaws: Prescriptions for a selfdesigning organization. Administrative Science Quarterly, 21: 41-65.

Hofer, C. W. (1980). Turnaround strategies. Journal of Business Strategy, 1(1): 19-31.

ISER - Instituto de Estudos da Religião, (1996). Novo Nascimento: os evangélicos em casa, na igreja e na política. Rio de Janeiro, RJ.

IBGE - Instituto Brasileiro de Geografia e Estatística. Censos Demográficos Brasileiros (1991, 2000, 2010).

Jacob, C. R., Hees, D. R., Waniez, P. \& Brustlein, V. (2003). Atlas da filiação religiosa e indicadores sociais no Brasil. Rio de Janeiro: PUC-Rio; São Paulo: Loyola.

Jacob, C. R.; Hees, D. R.; Waniez, P. (2013). Religião e território no Brasil: 1991/2010. Rio de Janeiro: Ed. PUC-Rio.

Kachani, M. (2012). Universal perde fieis para rival milagreira. Folha BR: Uol. Disponível em: <http://www1.folha.uol.com.br/poder/2012/04/107621 8-universal-perde-fieis-para-rival-milagre ira.shtml>. Acesso em: 31/10/2017.

Koksal, A. (2002). Predicting the development of decline in construction companies. Doctoral 
Dis sertation submitted to Illinois Institute of Tecnology, Illinois, Chicago.

Gilson, S. C. (1989). Management turnover and financial distress. Journal of Financial Economics, 25(2): $241-262$.

Lakatos, E. M.; Marconi, M. de A. (1991).

Metodologia do trabalho científico. São Paulo: Atlas.

Levy, A. (1986). Second-order planned change: Definition and conceptualization. Organizational Dynamics, 15(1): p. 5-20.

Mariano, R. (1996). Os neopentecostais e a teologia da prosperidade. Novos Estudos, São Paulo,

Cebrap, 44: 24-44.

Mariano, R. (2004). Expansão Pentecostal no Brasil: O caso da Igreja Universal. Estudos Avançados, São Paulo, 18(52): 121-138.

Martins, G. A. (2000). Manual para elaboração de monografias e dissertações. 2a Ed. São Paulo: Atlas.

Merton, R. K. (1959). Social theory and social structure. Glencoe: The Free Press.

Michels, R. (1949). Politicial parties. Glencoe: The Free Press.

Miller, D. \& Friesen, P. (1984). A Longitudinal Study of the Corporate Life Cycle. Management Science, 30(10): 1161-1183.

Mintzberg, H. (1984). Power and organization life cycles. Academy of Management Review, 9: 207-224.

Mintzberg, H. (1985). The Organization as Political Arena. Journal of Management Studies, 22(2): 133 154.

Mises, L. V. (1944). Bureaucracy. New Haven: Yale University Press.

Morais, U. I. do B. M. de, Figueiredo, L. Z. P. \& Zanotta,E. B. Igreja universal do Reino de Deus e marketing religioso. Revista Gerenciais, 3: 53-62.

Moulton, W. N. \& Thomas, H. (1993). Bankruptcy as a deliberate strategy: theoretical considerations and empirical evidence. Strategic Management Journal, 14(2): 125-135.

Neri, M. (2011). Novo Mapadas Religiões. Rio de Janeiro: FGV, CPS.

Nunes, E. (2007). Da burocracia para a profecia: mudanças no neopentecostalismo brasileiro.
Dissertação de mestrado. Universidade Presbiteriana Mackenzie, São Paulo, SP.

Oro, A. P. (2009). Transnacionalização religiosa no Cone Sul: uma comparação entre pentecostais e afro-religiosos. Debates do NER, 16: $225-245$

Oro, A. P. (2011). O Global e o Nacional num encontro evangélico internacional em Buenos Aires. Ciencias Sociales y Religion/Ciências Sociais e Religião, 14(13): 43-65.

Pereira, E. C. R. \& John, V. M. (2015). A venda da fé pela mídia: análise do discurso religioso apresentado no programa de TV da Igreja Mundial do Poder de Deus. Revista Anagrama, 9(2): 1-15.

Peretti, C., Copelli, F. A. \& Ferreira, M. C. (2011). Marketing e experiência religiosa: Encontro como Transcendente ou alienação? Artigo apresentado em Congresso de Teologia da Pontifícia Universidade Católica do Paraná 2011, Curitiba, Brasil.

Pfeffer, J. \& Salancick, G. R. (1978). The external control of organizations: a resource dependence perspective. New York: Harper \& Row.

Pires, F. F. \& Jesus, R. O. S. S. de. (2014). Do Brasil para o mundo: Como conceitos weberianos podem ajudar a entendero suces so transnacional da Igreja Mundial do Poder de Deus? Ciências da Religião: história e Sociedade, 12: 137-167.

Quinn, R. \& Cameron, K. (1983). Organizational life cycles and shifting criteria of effectiveness: some preliminary evidence. Management Science, 29(1): 3351.

Refkalefsky, E. (2006). Comunicação e

Posicionamento da Igreja Universal do Reino de Deus: um estudo de caso do Marketing Religioso. Artigo apresentado no $29^{\circ}$ Congresso Brasileiro de Ciências da Comunicação, Universidade de Brasilía, Brasília, Brasil.

Resende, P. J. P. de. (2006). Igreja Universal do Reino de Deus: Análise de um caso de sucesso de estratégia por diferenciação. Dis sertação de mestrado. Escola Brasileira de Administração Pública e de Empresa, Rio de Janeiro, RJ.

Ribeiro, J. W. (2005). Marketing como instrumento de manipulação da fé. In Apontamentos Midiáticos. Revista do Núcleo de Estudos e Pesquisas em Comunicação e Informação, - 1: 1-10. 
Ribeiro, J. W. \& Pinto, F. S. (2009). A Mídia e a Igreja Universal. Artigo apresentado no Congresso Brasileiro de Ciência da Comunicação 2009, Santos, Brasil.

Robbins, D. K. \& Pearce, J. A. (1992). Turnaround: retrenchment and recovery. Strategic Management Journal, 13(4): 287-309.

Rocha, D. A. (2011). Metodologia Utilizada pela Igreja Mundial do Poder de Deus na formação da concepção de cura. Revista de Ciências Humanas e Letras das Faculdades Integradas da Fama. 3(2): 1-15.

Rocha, D. \& Zorzin, P. (2012). Os evangélicos em números: algumas observações sobre o que revelou $(e$ o que não revelou) o estudo Novo Mapa das Religiões sobre o agregado evangélico brasileiro. Anais dos Simpósios da ABHR, v. 13.

Sá, R. C. R. de. (1995). Universidades Federais Brasileiras: Uma contribuição à discussão sobre crise e declínio nas organizações. Tese de doutorado, Escola de Administração de Empresas da Fundação Getúlio Vargas, São Paulo, SP.

Scott, W. G. (1976). The management of decline. Conference Board Record, p. 56-59.

Serafim, M. C., Martes, A. C. B. \& Rodriguez, C. L. (2012). "Segurando na Mão de Deus": Organizações Religiosas e Apoio ao Empreendedorismo. Revista de Administração de Empresas (RAE). 52(2): 217-231.

Serra, F., Ferreira, M. \& Almeida, M. (2013). Organizational decline: a yet largely neglected topic in organizational studies. Management Research: The Journal of the Iberoamerican Academy of Management, 11(2): 133-156.

Serra, F. A. R., Pinto, R., Guerrazzi, L. \& Ferreira, M. P. (2017). Organizational Decline Research Review: Challenges and Issues for a future research Agenda. Brazilian Administration Review, 14(2): 1-27.

Serra, F. A. R. (2017) Comentário Editorial - A Importância da Pesquisa Baseada em fenômenos em Estratégia para os Pesquis adores Iberoamericanos Revista Ibero-Americana de Estratégia, 16 (2).

Shamir, B., House, R. J. \& Arthur, M. B. (1993). The motivational effects of charismatic leadership: A selfconcept based theory. Organizational Science, 4: 1-17.
Silva, E. L. \& Menezes, E. M. (2001). Metodologia da pesquisa e elaboração de dissertação. 3. ed. Florianópolis: Laboratório de Ensino a Distância da UFSC.

Smart, C., \& Vertinsky, I. (1977). Designs for crisis decision units. Administrative Science Quarterly, 22(4): 640-657.

Starbuck, W. H., Greve, A. \& Hedberg, B. (1978). Responding to crisis. Journal of Business Administration, 9(2): 111-137.

Staw, B. M., Sandelands, L. E. \& Dutton, J. E. (1981). Threat-rigidity effects in organizational behavior: a multilevel analysis. Administrative Science Quarterly, 26(4): $501-524$.

Sutton, R. I. \& Callahan, A. L. (1987). The stigma of bankruptcy: spoiled organizational image and its management. Academy of Management Journal, 30(3): 405-436.

Thompson, J. D. (1967). Organizations in action. New York: McGraw-Hill.

Tillich, P. (2000). História do Pensamento Cristão. São Paulo: ASTE.

Torres, A. P., Serra, F. A., Almeida, M. R, \& Ferreira, M. P. (2013). O Declínio de uma empresa Brasileira de Grande Porte: O caso Gradiente. Revista de Administração e Contabilidade da Usinos 10(3): 273292.

Trahms, C., Ndofor, H. \& Sirmon, D. (2013).

Organizational decline and turnaround: a review and agenda for future research. Journal of Management, 39(5): 1277-1307.

Whetten, D. A. (1980). Organizational Decline: A Neglected Topic In Organizational Science. Academy of Management Review, 5(4): 577-588.

Whetten, D. (1987). Organizational growth and decline process. Annual Review of Sociology, 13: 335-358.

Zammuto, R. F. \& Cameron, K. S. (1985). Environmental decline and organizational response. Research in Organizational Behavior, 7: 223-263. 